\title{
Reactivity ratios of controlled/living copolymerization of styrene and acrylonitrile in ionic liquid microemulsion
}

\author{
Guo-Xiang Wang • Mang Lu • Zhao-Hui Hou $\cdot$ Hu Wu
}

Received: 11 August 2012 / Accepted: 6 January 2013 /Published online: 25 January 2013

(C) The Author(s) 2013. This article is published with open access at Springerlink.com

\begin{abstract}
In this work, reverse atom transfer radical copolymerization of styrene and acrylonitrile was investigated at $65^{\circ} \mathrm{C}$ in ionic liquid microemulsion using $2,2^{\prime}$-azobis(isobutyronitrile) (AIBN) as initiator, $\mathrm{FeCl}_{3} \cdot 6 \mathrm{H}_{2} \mathrm{O} /$ succnic acid as catalyst complex, and hexadecyl trimethyl ammonium bromide as surfactant. The copolymers of styrene and acrylonitrile (SAN) with predetermined molecular weights and narrow molecular weight distribution were obtained. Results showed that the polymerization proceeded in a controlled/'living' process in which the molecular weight of SAN increased with increasing the monomer conversion. The size of the resulting SAN particle was investigated. The monomer reactivity ratios increased with increasing the molar ratio of acrylonitrile to styrene. The obtained polymer was characterized by ${ }^{13} \mathrm{C} \mathrm{nu}-$ clear magnetic resonance and gel permeation chromatography. The living characteristics were demonstrated by chain extension experiment.
\end{abstract}

Keywords Styrene $\cdot$ Acrylonitrile $\cdot$ Living polymerization · Ionic liquid based microemulsion

\section{Introduction}

The living radical polymerization offers an attractive route to synthesize polymers with well-defined structures [1]. Three radical polymerization techniques have been extensively

G.-X. Wang $\cdot$ Z.-H. Hou $(\bowtie) \cdot H$. Wu

College of Chemistry and Chemical Engineering,

Hunan Institute of Science and Technology, Yueyang 414006,

Hunan Province, China

e-mail: zhqh96@163.com

M. Lu

School of Materials Science and Engineering, Jingdezhen Ceramic Institute, Jingdezhen 333403, Jiangxi Province, China studied: nitroxide-mediated living radical polymerisation (NMP) [2, 3], atom transfer radical polymerization mediated by a transition metal complex (ATRP) [4-6] and reversible addition fragmentation chain transfer polymerization (RAFT) [7, 8]. Among them, ATRP was a robust technique and has been applied under heterogeneous conditions in suspension [9, 10], dispersion [11], ab initio emulsion [12], seeded emulsion [13], miniemulsion [14, 15] and microemulsion $[12,16,17]$.

Microemulsions are clear, thermodynamically stable, isotropic liquid mixtures of oil, water and surfactant, frequently in combination with a cosurfactant. In contrast to ordinary emulsions, microemulsions form upon simple mixing of the components and do not require the high shear conditions generally used in the formation of ordinary emulsions. However, there are some limits on conducting ATRP in microemulsion, for example, higher amount of surfactant compared with conventional emulsion polymerization and solubility limitations for apolar solutes remains. The limits can be overcome by ionic liquid microemulsion due to the combined advantages of both ionic liquids and microemulsions.

Ionic liquid is a salt in which the ions are poorly coordinated, resulting in these solvents being liquid below $100{ }^{\circ} \mathrm{C}$, or even at room temperature (room temperature ionic liquids, RTIL's). RTILs are developed to replace traditional organic solvents and used in microemulsion to widen the application fields of ionic liquid. Ionic liquid microemulsion as a 'green solvent' has been extensively investigated in varied fields of biocatalysis [18], polymerization [19-22], nanoparticle [23] and organic synthesis [24].

Reverse atom transfer radical polymerization (RATRP) is one of improved ATRP techniques. In a RATRP system, it was not sensitive to air due to higher oxidation transition metals used. Iron complex catalyst is one of the most commonly transition metals and has been applied in 
controlled/living polymerization [25-28]. Iron was easily complexed with more environmentally friendly organic acid [29-31].

Copolymers (SAN) of styrene (St) and acrylonitrile (AN) have been applied in numerous fields due to its outstanding chemical and mechanical properties. Its application would be further enhanced by an additional control of molecular weights, molecular weight distribution (MWD), and chain topology. There are some reports about controlled/living copolymerization of styrene and acrylonitrile [32-34]. To the authors' knowledge, there are no reports about controlled/living copolymerization of styrene and acrylonitrile in ionic liquid microemulsion.

In this study, copolymerizations of styrene and acrylonitrile were conducted in ionic liquid microemulsion under reverse atom transfer radical polymerization using 2,2'-azobis(isobutyronitrile) (AIBN) as initiator, $\mathrm{FeCl}_{3} \cdot 6 \mathrm{H}_{2} \mathrm{O} /$ Succinic acid (SA) as complex catalyst, cetytrimethylammonium bromide (CTAB) as surfactant and 1-butyl-3-methylimidazolium hexafluorophate $\left([\mathrm{bmim}]\left[\mathrm{PF}_{6}\right]\right)$ as ionic liquid. The endfunctionality of the copolymers was estimated from the chain extension reaction.

\section{Experimental}

\section{Materials}

The ionic liquid [bmim] $\left[\mathrm{PF}_{6}\right]$ was purchased from Aladdin Reagents Co., Ltd, Shanghai, China. Styrene (Analytic Reagent grade, AR grade) was purchased from Tianjin Fuchen Chemical Reagents Factory, China. It was distilled under reduced pressure prior to use. Acrylonitrile (Analytic Reagent grade, AR grade) was purchased from Tianjin Bodi Chemical Holding Co., Ltd., China. It was distilled under reduced pressure prior to use. AIBN, obtained from Shanghai Chemical Holding Co., Ltd, China, was recrystallized twice from methanol. Ferric chloride hexahydrate was purchased from Shanghai Qingfeng Chemical Factory, China. Succinic acid (SA, Analytic Reagent grade, AR grade), was purchased Chongqing Chuangdong Chemical (Group) Co., Ltd, China. Benzoyl peroxide (BPO) and hexadecyl trimethyl ammonium bromide (CTAB) was obtained from Sinopharm Chemical Reagent Co., Ltd., Shanghai, China. BPO was recrystallized twice from ethanol. Other regents were used as received.

\section{Polymerization procedure}

The microemulsion systems were prepared by dissolving $\mathrm{CTAB}$ in ionic liquid in a $100 \mathrm{~mL}$ three-neck round-bottom flask equipped with magnetic stirring bar. Then the monomer, $\mathrm{FeCl}_{3} \cdot 6 \mathrm{H}_{2} \mathrm{O}$ and succinic acid were added. Finally, AIBN was added. The mixture was mildly stirred until the transparent homogeneous phase was reached. The flask was degassed three times under vacuum, and flushed with nitrogen. Then the flask was placed in an oil bath held by a thermostat at $65^{\circ} \mathrm{C}$. After the desired time, the polymerizations were stopped by immersing into ice water. The copolymer samples were precipitated by a large quantity of methanol. The obtained copolymers were purified by repeated washing with methanol, and then vacuum-dried at $60^{\circ} \mathrm{C}$ for 1 day until constant weight.

In a typical experiment, the molar ratio of [AN+ $\mathrm{St}]:[\mathrm{AIBN}]:\left[\mathrm{FeCl}_{3} \cdot 6 \mathrm{H}_{2} \mathrm{O}\right]:[\mathrm{SA}]$ was fixed at $500: 1: 1: 2$, and the molar ratio of AN to St was 0.45:0.55. Thus, a dry flask was charged with $6.2520 \mathrm{~g}$ [bmim] $\left[\mathrm{PF}_{6}\right](22 \mathrm{mmol})$ and $2.5000 \mathrm{~g} \mathrm{CTAB}(7 \mathrm{mmol})$ and mixed, then $0.4775 \mathrm{~g} \mathrm{AN}$ (9 mmol), $1.1440 \mathrm{gSt}(11 \mathrm{mmol}), 0.0108 \mathrm{~g} \mathrm{FeCl}_{3} \cdot 6 \mathrm{H}_{2} \mathrm{O}$ $(0.04 \mathrm{mmol}), 0.0094 \mathrm{~g}$ Succinic acid $(0.08 \mathrm{mmol})$ and $0.0066 \mathrm{~g}$ AIBN $(0.04 \mathrm{mmol})$ were in turn added to the flask.

\section{Measurements}

Monomer conversion was determined by gravimetric analysis at different intervals. The conversion (C) was determined by the following formula:

$\mathrm{C} \%=\mathrm{W}_{2} / \mathrm{W}_{1} \times 100 \%$

Where $\mathrm{W}_{1}$ was the initial weight of the comonomers and $\mathrm{W}_{2}$ was the weight of the obtained copolymer.

The number-average molecular weights $\left(\mathrm{M}_{\mathrm{n}, \mathrm{GPC}}\right)$ and MWDs of the resulting SAN were determined by gel permeation chromatography (GPC), conducted with a Waters 1515 equipped with refractive index detector using tetrahydrofuran (THF) as a mobile phase at a flow rate of $1.0 \mathrm{~mL} / \mathrm{min}$ at $35{ }^{\circ} \mathrm{C}$. Linear polystyrene standards were used to calibrate the columns.

${ }^{13} \mathrm{C}$ NMR spectrum was recorded for the polymer samples on a Bruker $400 \mathrm{MHz}$ Spectrometer using $\mathrm{CDCl}_{3}$ as the solvent at ambient temperature and tetramethylsilane as the internal standard.

Particle size was determined by using Malvern Mastersizer 2000 equipment. The particle size distribution obtained was based on volume, i.e., the particle size interval obtained represented the total volume (\%) of all particles with a diameter included in this interval in relation to the total volume of all particles in the distribution.

\section{Results and discussion}

Reverse atom transfer radical copolymerization of St and $\mathrm{AN}$ in ionic liquid microemulsion

The feasibility of reverse atom transfer radical copolymerization of St and $\mathrm{AN}$ was investigated in ionic liquid 
Scheme 1 Preparation of SAN copolymerization by RATRP in ionic liquid microemulsion

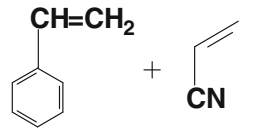

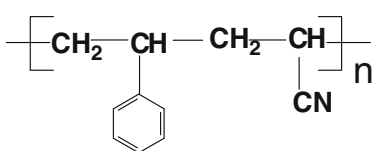

microemulsion. SAN copolymer was prepared by RATRP process using $\mathrm{FeCl}_{3} /$ succinic acid (SA)/AIBN catalyst system in ionic liquid microemulsion as described in Scheme 1.

Figure 1 shows the semilogarithmic kinetic plots for the reverse atom transfer copolymerization with varied molar ratios of St/AN. As shown in Fig. 1, a linear relationship between $\ln \left([\mathrm{M}]_{0} /[\mathrm{M}]\right)$ and time was observed, indicating first-order kinetics with respect to monomer consumption and a constant radical concentration during the polymerization process. The copolymerization rate increased with the increase of AN monomer feed until the molar ratio of AN/St was 50:50, and then the copolymerization rate decreased with the increase of AN monomer feed. This is due to the formation of charge transfer complex. Similar results were reported by Hill et al. [33].

Figure 2 shows the dependence of the number average molecular weight $(\mathrm{Mn})$ and the polydispersities (PDI) of the obtained SAN versus monomer conversion at different molar ratios of AN/St. As shown, the molecular weights of the resulting SAN copolymers measured by GPC increased with monomer conversion. Furthermore, in most cases, the molecular weight distributions were below 1.3. The results indicated that copolymerization of $\mathrm{AN} / \mathrm{St}$ proceeded in a controlled/living fashion. However, at the beginning of copolymerization, some higher molecular weights were obtained due to incomplete decomposition of AIBN. The copolymerization proceeded in a

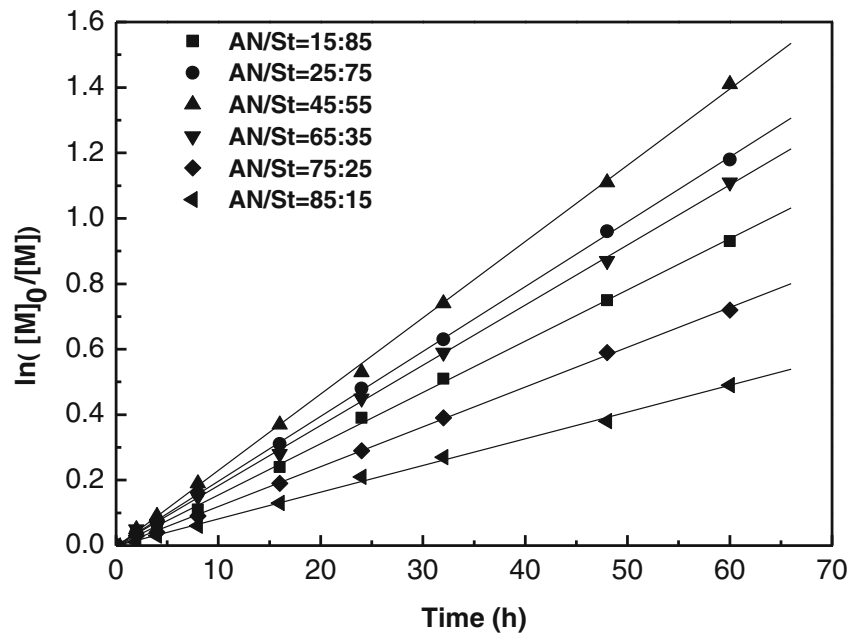

Fig. 1 Plots of $\ln \left([\mathrm{M}]_{0} /[\mathrm{M}]\right)$ versus time of reverse atom transfer copolymerization of AN and St in ionic liquid microemulsion at $65^{\circ} \mathrm{C}$ at various monomer molar ratios conventional radical polymerization. This was further confirmed by broader molecular weight distribution during the initial polymerization.

SAN copolymer for ionic liquid microemulsion system was determined using ${ }^{13} \mathrm{C}$ nuclear magnetic resonance spectroscopy. Figure 3 shows ${ }^{13} \mathrm{C}$ NMR spectrum of the resulting SAN copolymer. The peaks at 120.6-121.8 ppm were assigned to the group of $\mathrm{CN}$. The signals at $126.1-$ $130.4 \mathrm{ppm}$ were attributed to the aromatic ring group. The signals at 25.3-27.3 ppm corresponded to the methine group of $\mathrm{CH}$. The signals at $35.8-41.6 \mathrm{ppm}$ were attributed to the methylene group of $\mathrm{CH}_{2}$.

The particle size distribution is shown in Fig. 4. Particle size showed a distribution between 5 and $60 \mathrm{~nm}$, with irregular peaks between 10.1 and $20 \mathrm{~nm}$.

\section{Monomer reactivity ratios calculated from ${ }^{13} \mathrm{C}$ NMR spectrum}

According to the literature [34], Fineman-Ross and Kelen-Tudos methods were not used to calculate the reactivity ratios of copolymerization of St and AN because it was difficult to obtain linear plots. A series of experiments with different feed molar ratios were carried out under the same experimental conditions and the components were determined by ${ }^{13} \mathrm{C}$ NMR (Fig. 5). The reactivity ratios can be calculated by the following equation:

$r_{S t}=\frac{f_{A N}}{f_{S t}}\left(\frac{1}{P_{(A N / S t)}}-1\right) \quad r_{A N}=\frac{f_{S t}}{f_{A N}}\left(\frac{1}{P_{(S t / A N)}}-1\right)$

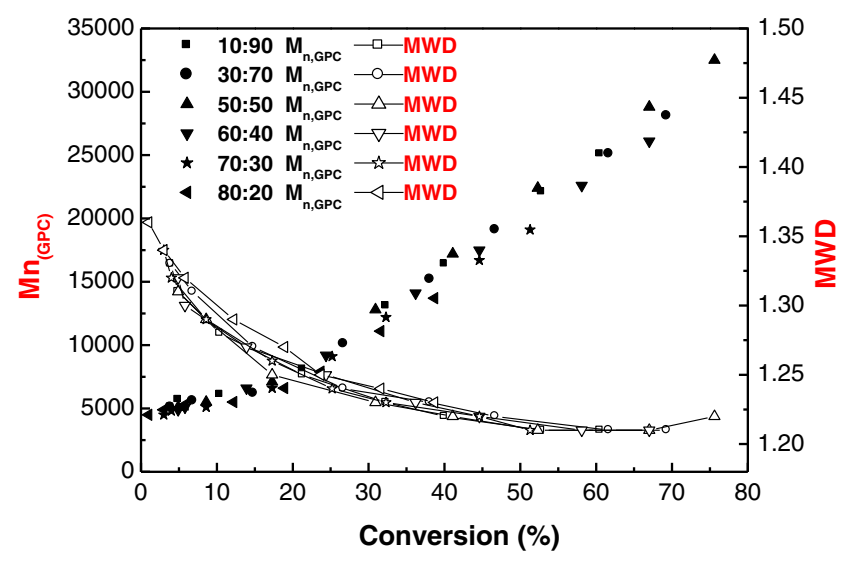

Fig. 2 Dependence of $M_{n, G P C}$ and PDI on monomer conversion for reverse atom transfer copolymerization of $\mathrm{St}$ and $\mathrm{AN}$ at $65^{\circ} \mathrm{C}$ in ionic liquid microemulsion 


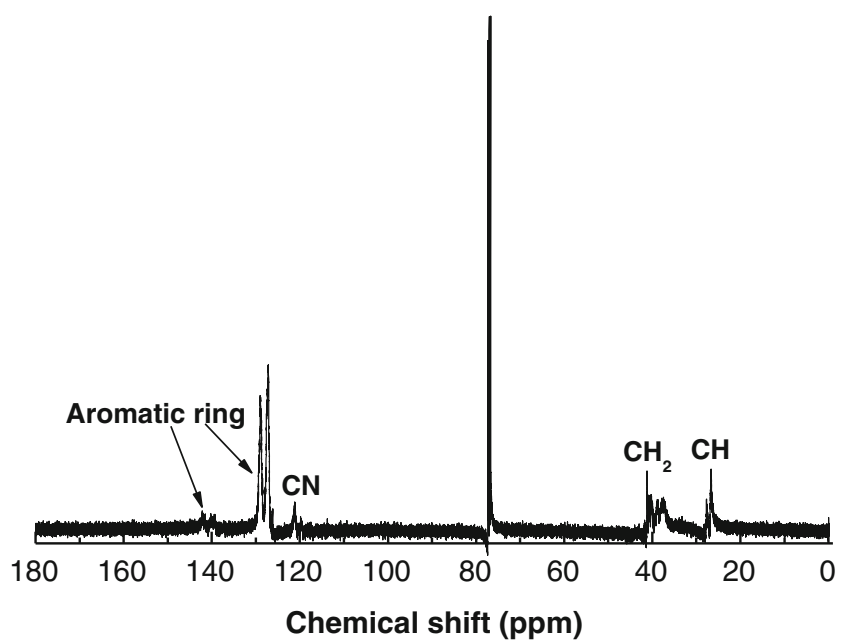

Fig. $3{ }^{13} \mathrm{C}$ spectrum of copolymer of $\mathrm{AN}$ and $\mathrm{St}$ in $\mathrm{CDCl}_{3}$

Where

$P_{(S t / A N)}=\frac{F_{S A S}+F_{S A A} / 2}{F_{A A A}+F_{A A S}+F_{S A S}} \quad P_{(A N / S t)}=\frac{F_{A S A}+F_{S S A} / 2}{F_{S S S}+F_{S S A}+F_{A S A}}$

In Eq. (1), $\mathrm{F}_{\mathrm{AAA}}, \mathrm{F}_{\mathrm{SAA}}, \mathrm{F}_{\mathrm{SAS}}, \mathrm{F}_{\mathrm{SSS}}, \mathrm{F}_{\mathrm{SSA}}$, and $\mathrm{F}_{\mathrm{ASA}}$ were the amount of the assignments of the resonances of AN- and St-centered triads in the ${ }^{13} \mathrm{C}$ NMR spectrum: AAA $(\delta=118$ $119.2 \mathrm{ppm})$, SAA or AAS $(\delta=119.2-120.8 \mathrm{ppm})$, SAS $(\delta=$ $120.8-122.5 \mathrm{ppm})$ for AN centered triads; SSS $(\delta=143.7-$ $146.8 \mathrm{ppm})$, SSA or ASS $(\delta=141.2-143.7 \mathrm{ppm})$, ASA $(\delta=$ $138.7-1141.2 \mathrm{ppm}$ ) for St centered triads, respectively. And $\mathrm{f}_{\mathrm{AN}}$ and $\mathrm{f}_{\mathrm{St}}$ are the feed ratios of $\mathrm{AN}$ and St, respectively.

The triads distributions were determined according to what was reported by Hill [33]. The triads distributions were calculated from the area under peaks for the respective triads. For example, the feed molar ratio of $\mathrm{AN}$ :St was $15: 85, F_{\mathrm{SSS}}$ was equal to the ratio of the integral area of SSS $(\delta=143.7-146.8 \mathrm{ppm})$ and total area of SSS $(\delta=143.7-$

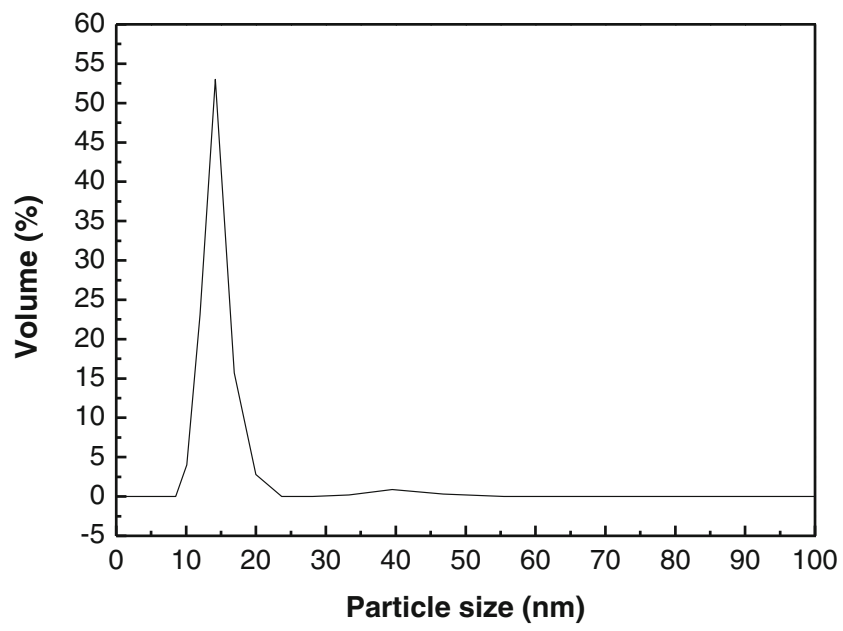

Fig. 4 The particle size distribution of SAN copolymer prepared in ionic liquid microemulsion

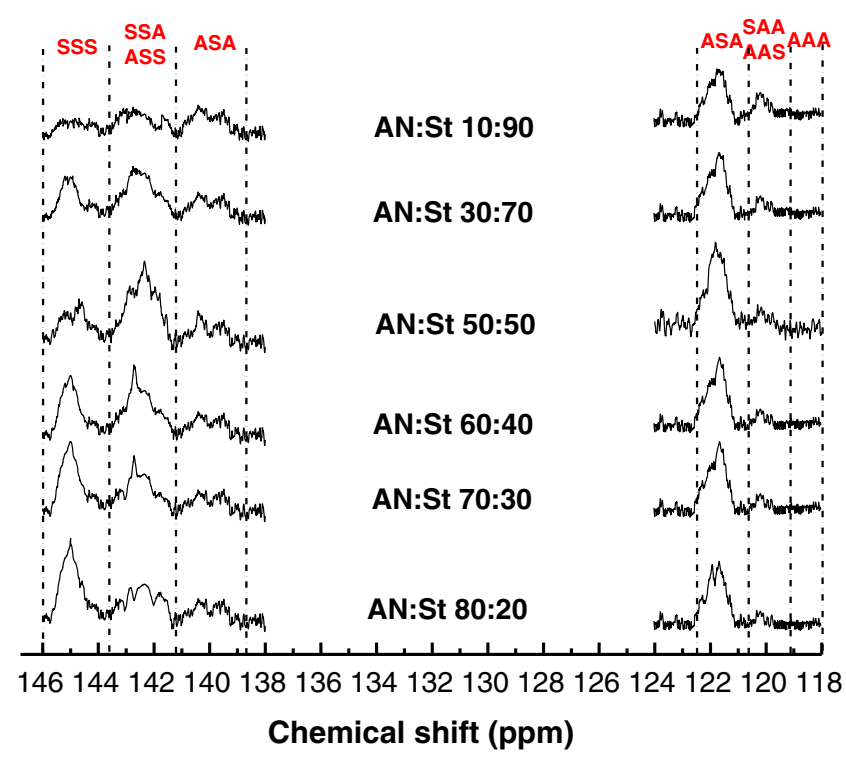

Fig. $5{ }^{13} \mathrm{C}$ NMR spectra indicating the evolution of the intensity of nitrile carbon regions and aromatic carbon regions during copolymerization in ionic liquid microemulsion

$146.8 \mathrm{ppm})$, SSA or ASS $(\delta=141.2-143.7 \mathrm{ppm})$ and ASA $(\delta=138.7-1141.2 \mathrm{ppm})$. The results were summarized in Table 1. When the molar ratios of AN:St changed from $15: 85$ to $85: 15$, the reactivity ratios of AN and St were from 1.039 to 0.003 and from 1.084 to 2.149 , respectively. The reactivity ratios calculated from Fig. 5 were shown in Fig. 6. The obtained reactivity ratios in this work are different from that of reported conventional microemulsion copolymerization of St and AN $\left(\mathrm{r}_{\mathrm{St}}=0.61-2.98, \mathrm{r}_{\mathrm{AN}}=0-0.039\right)[35]$. The reported reactivity ratios for the controlled/living copolymerization of St and AN calculated by the Jaacks's method were $\mathrm{r}_{\mathrm{St}}=0.46$, $\mathrm{r}_{\mathrm{AN}}=0.19[36]$. The deviation of reactivity ratios may be due to different reaction media and different mechanism.

$\mathrm{BPO}$ as initiator in reverse atom transfer copolymerization of $\mathrm{AN}$ and $\mathrm{St}$ in ionic liquid microemulsion

In this work, AIBN was replaced by BPO. The molar ratio of [AN]:[St] was fixed at $0.45: 0.55$ and the molar ratio of

Table 1 The triads distributions in SAN

\begin{tabular}{|c|c|c|c|c|c|c|c|c|}
\hline \multirow[t]{2}{*}{ Molar ratio } & \multicolumn{3}{|c|}{ St-centred triads } & \multicolumn{3}{|c|}{ AN-centred triads } & \multirow[t]{2}{*}{$\mathrm{r}_{\mathrm{AN}}$} & \multirow[t]{2}{*}{$\mathrm{r}_{\mathrm{St}}$} \\
\hline & $\mathrm{F}_{\mathrm{SSS}}$ & $\mathrm{F}_{\mathrm{SSA}}$ & $\mathrm{F}_{\mathrm{ASA}}$ & $\mathrm{F}_{\mathrm{AAA}}$ & $\mathrm{F}_{\mathrm{AAS}}$ & $\mathrm{F}_{\mathrm{SAS}}$ & & \\
\hline $\mathrm{AN}: \mathrm{St}=15: 85$ & 0.75 & 0.22 & 0.03 & 0.01 & 0.29 & 0.70 & 1.039 & 1.084 \\
\hline $\mathrm{AN}: \mathrm{St}=25: 75$ & 0.61 & 0.32 & 0.07 & 0.01 & 0.18 & 0.81 & 0.333 & 1.116 \\
\hline $\mathrm{AN}: \mathrm{St}=45: 55$ & 0.33 & 0.55 & 0.12 & 0.02 & 0.12 & 0.86 & 0.106 & 1.253 \\
\hline $\mathrm{AN}: \mathrm{St}=65: 35$ & 0.28 & 0.44 & 0.28 & 0.01 & 0.07 & 0.92 & 0.025 & 1.857 \\
\hline $\mathrm{AN}: \mathrm{St}=75: 25$ & 0.20 & 0.42 & 0.38 & 0.02 & 0.04 & 0.94 & 0.014 & 2.085 \\
\hline $\mathrm{AN}: \mathrm{St}=85: 15$ & 0.15 & 0.25 & 0.60 & 0.01 & 0.01 & 0.98 & 0.003 & 2.149 \\
\hline
\end{tabular}




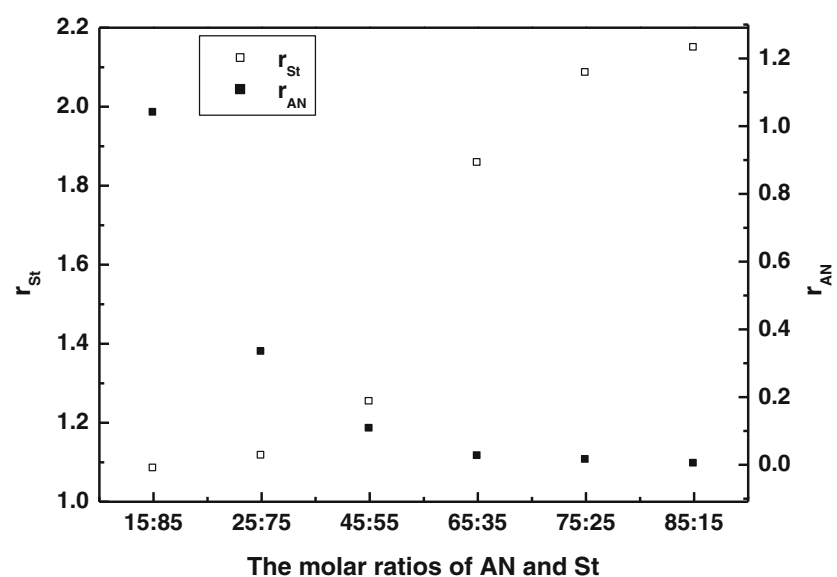

Fig. 6 The reactivity ratios of $r_{S t}$ and $r_{A N}$ with the molar ratios of AN and $\mathrm{St}$

$[\mathrm{AN}+\mathrm{St}]:\left[\mathrm{FeCl}_{3} \cdot 6 \mathrm{H}_{2} \mathrm{O}\right]:[\mathrm{SA}]$ was fixed at 500:1:2. A series of experiments were carried out with varying the molar ratio of $[\mathrm{AN}+\mathrm{St}]:[\mathrm{BPO}]$. As listed in Table 2, a well-controlled copolymerization of AN and St was achieved in this system, as determined by the molecular weights of the resulting SAN increasing with monomer conversion and the MWD values below 1.30. It demonstrated that BPO can be served as efficient initiator in this system.

\section{Chain extension of SAN}

A predetermined quantity of SAN as macroinitiator (obtained in ionic liquid microemulsion) was added to ionic liquid microemulsion in a dried $100 \mathrm{~mL}$ three-neck flask. The molar ratio [St]:[macroinitiator]:[ $\left[\mathrm{FeCl}_{2}\right]:[\mathrm{SA}]$ was kept at 500:1:1:2. The chain extension of SAN was performed as follows: $6.2520 \mathrm{~g}$ [bmim] $\left[\mathrm{PF}_{6}\right](22 \mathrm{mmol})$ and $2.5000 \mathrm{~g} \mathrm{CTAB}(7 \mathrm{mmol})$ were fed and mixed, then $2.080 \mathrm{gSt}(20 \mathrm{mmol}), 0.0051 \mathrm{~g} \mathrm{FeCl}_{2}$ $(0.04 \mathrm{mmol}), 0.0094 \mathrm{~g}$ Succinic acid $(0.08 \mathrm{mmol})$ and $0.5120 \mathrm{~g}$ macroinitiator $(\mathrm{Mn}=12,800 \mathrm{~g} / \mathrm{mol}, \mathrm{MWD}=1.23)(0.04 \mathrm{mmol})$ were in turn added to the flask. After degassed, $\mathrm{N}_{2}$ was charged. The cycle was three times. The polymerization was conducted at $65^{\circ} \mathrm{C}$. As shown in Fig. 7, the molecular weight increased from $12,800 \mathrm{~g} / \mathrm{mol}$ to $36,400 \mathrm{~g} / \mathrm{mol}$ and the MWD also increased from 1.23 to 1.33 indicating that the SAN with

Table 2 Effect of the amount of BPO on reverse atom transfer radical copolymerization of $\mathrm{AN}$ and $\mathrm{St}$ at $65^{\circ} \mathrm{C}$

\begin{tabular}{lllllll}
\hline Run & $\begin{array}{l}\text { Ratio of } \\
{[\mathrm{AN}+\mathrm{St}]_{0} /} \\
{[\mathrm{BPO}]_{0}}\end{array}$ & $\begin{array}{l}\text { Time } \\
(\mathrm{h})\end{array}$ & $\begin{array}{l}\text { Conversion } \\
(\%)\end{array}$ & $\begin{array}{l}\mathrm{M}_{\mathrm{n}, \text { theo }}{ }^{\mathrm{a}} \\
\left(\mathrm{gmol}^{-1}\right)\end{array}$ & $\begin{array}{l}\mathrm{M}_{\mathrm{n}, \mathrm{GPC}} \\
\left(\mathrm{gmol}^{-1}\right)\end{array}$ & MWD \\
\hline 1 & $250: 1$ & 33.6 & 56.4 & 22863 & 23800 & 1.29 \\
2 & $500: 1$ & 28.3 & 47.2 & 19134 & 21100 & 1.26 \\
3 & $750: 1$ & 31.2 & 48.6 & 19701 & 21400 & 1.28 \\
\hline
\end{tabular}

a: $\mathrm{M}_{\mathrm{n} \text {,theo }}=[([\mathrm{AN}]+[\mathrm{St}]) /[\mathrm{BPO}]] \times$ conversion $\times\left(\mathrm{f}_{\mathrm{AN}} \times \mathrm{Mw}_{\mathrm{AN}}+\mathrm{f}_{\mathrm{St}} \times \mathrm{Mw}_{\mathrm{St}}\right)$

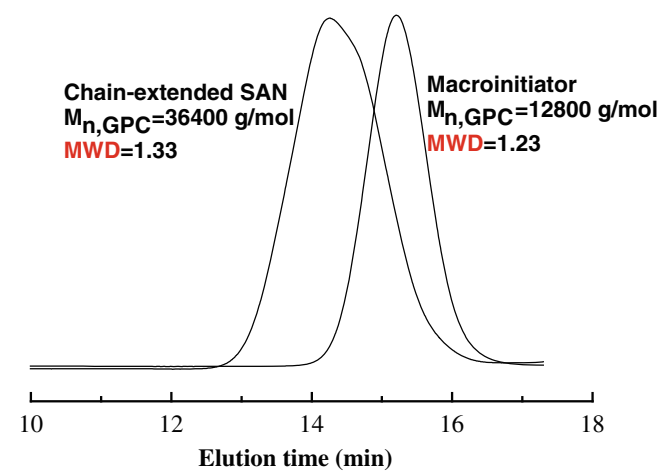

Fig. 7 GPC traces of macroinitiator and chain-extended PSt using SAN prepared by reverse atom transfer radical copolymerization of $\mathrm{AN}$ and St with the obtained SAN as a macroinitiator

chlorine end groups synthesized by using these initiator/catalyst/ionic liquid microemulsion systems can initiate reverse atom transfer copolymerization quantitatively to prepare the well-defined SAN with narrow MWD.

\section{Conclusion}

Reverse atom transfer radical copolymerization of acrylonitrile and styrene were successfully carried out in ionic liquid microemulsion with AIBN as initiator in the presence of $\mathrm{FeCl}_{3} \cdot 6 \mathrm{H}_{2} \mathrm{O} / \mathrm{SA}$ complexes catalyst. The copolymerization proceeded in a controlled/living fashion, as evidenced by the first-order kinetics and the linear increase of the numberaverage molecular weight with conversion. The particle size distribution of the obtained SAN copolymer was about 10 $20 \mathrm{~nm}$ determined by Malvern Mastersizer equipment. The monomer reactivity ratio of AN and St copolymerization in ionic liquid microemulsion was determined by ${ }^{13} \mathrm{C}$ NMR spectroscopic analysis and varied from 1.039 to 0.003 for $\mathrm{AN}$ and from 1.084 to 2.149 for St when the monomer feed molar ratio of AN and St changed from 15:85 to 85:15. BPO was also an efficient in this system. The resulting SAN copolymer with a chlorine-terminated atom was activated during the chain extension experiment.

Acknowledgments The financial support from the Science and Technology Planning Project of Hunan Province, China (No. 2012FJ4272).

Open Access This article is distributed under the terms of the Creative Commons Attribution License which permits any use, distribution, and reproduction in any medium, provided the original author(s) and the source are credited.

\section{References}

1. Braunecker WA, Matyjaszewski K (2007) Prog Polym Sci 32:93

2. Georges MK, Veregin RPN, Kazmaier PM, Hamer GK (1993) Macromolecules 26:2987 
3. Hawker CJ, Bosman AW, Harth E (2001) Chem Rev 101:3661

4. Matyjaszewski K, Xia J (2001) Chem Rev 101:2921

5. Kamigaito M, Ando T, Sawamoto M (2001) Chem Rev 101:3689

6. Matyjaszewski K, Patten TE, Xia J (1997) J Am Chem Soc 119:674

7. Moad G, Rizzardo E, Thang SH (2005) Aust J Chem 58:379

8. Coote ML (2004) Macromolecules 37:5023

9. Granel C, Dubois P, Jerome R (1996) Macromolecules 29:8576

10. Nishikawa T, Kamigatio M, Sawamoto M (1999) Macromolecules 32:2204

11. Min K, Matyjaszewski K (2009) Cent Eur J Chem 7:657

12. Min K, Gao H, Matyjaszewski K (2006) J Am Chem Soc 128:10521

13. Okubo M, Minami H, Zhou J (2004) Colloid Polym Sci 282:747

14. Min K, Jakubowski W, Matyjaszewski K (2006) Macromol Rapid Commun 27:594

15. Khezrollah K, Vahid H-A, Hossein R-M, Mehdi S-K (2012) J Polym Res 19:1

16. Kagawa Y, Kawasaki M, Zetterlund P, Minami H, Okubo M (2007) Macromol Rapid Commun 28:2354

17. Min K, Matyjaszewski K (2005) Macromolecules 38:8131

18. Erbeldinger M, Mesiano AJ, Russell AJ (2000) Biotechnol Prog $16: 1129$

19. Lade O, Co CC, Cotts P, Strey R, Kaler EW (2005) Colloid Polym Sci 283:905

20. Chen Z, Yan F, Qiu L, Lu J, Zhou Y, Chen J, Tang Y, Texter J (2010) Langmuir 26:3803
21. Zhou Y, Qiu L, Deng Z, Texter J, Yan F (2011) Macromolecules 44:7948

22. Wang GX, Lu M, Zhong M, Wu H (2012) J Polym Res 19:9782

23. Li Z, Zhang J, Du J, Han B, Wang J (2006) Colloids Surf A 286:117

24. Zhang GP, Zhou HH, Hu JQ, Liu M, Kuang YF (2009) Green Chem 11:1428

25. Wang Y, Zhang Y, Parker B, Matyjaszewski K (2011) Macromolecules 44:4022

26. Wang Y, Matyjaszewski K (2011) Macromolecules 44:1226

27. Zhu GH, Zhang LF, Zhang ZB, Zhu J, Tu YF, Cheng ZP, Zhu XL (2011) Macromolecules 44:3233

28. Wang GX, Lu M, Wu H (2012) Polymer 53:1093

29. Zhang LF, Cheng ZP, Shi SP, Li QH, Zhu XL (2008) Polymer 49:3054

30. Wang GX, Wu H (2011) Polym Bull 67:1809

31. Chen H, Liang Y, Liu DL, Tan Z, Zhang SH, Zheng ML, Qu RJ (2010) Mater Sci Eng 30:605

32. Pietrasik J, Dong HC, Matyjaszewski K (2006) Macromolecules 39:6384

33. Al-Harthi M, Sardashti A, Soares JBP, Simon LC (2007) Polymer 48:1954

34. Tsarevsky NV, Sarbu T, Gobelt B, Matyjaszewski K (2002) Macromolecules 35:6142

35. Lee KC, Gan LM, Chew CH, Ng SC (1995) Polymer 36:3719

36. Fan DQ, He JP, Xu JT, Tang W, Liu Y, Yang YL (2006) J Polym Sci A Polym Chem 44:2260 